\title{
Development of UPLC-MS/MS Method for Quantitative Analysis of Curcumin in Human Plasma
}

\author{
Hayun Hayun*, Rina Rahmawati, Yahdiana Harahap and Santi Purna Sari \\ Faculty of Pharmacy, Universitas Indonesia, Depok 16424, West Java, Indonesia
}

Received: 21 October 2016; accepted: 14 May 2017

\begin{abstract}
A specific, very rapid, and sensitive ultra-performance liquid chromatography-tandem mass spectrometry (UPLC-MS/ MS) method for quantitative analysis of curcumin in human plasma has been developed and validated. Diazepam was used as internal standard (IS). The analytes were isolated using liquid-liquid extraction method with the mixture of ethyl acetate-methanol (95:5). The organic solvents were evaporated, reconstituted in mobile phase, and injected to UPLC completed with UPLC BEH C18 column $1.7 \mu \mathrm{m}, 2.1 \times 100 \mathrm{~mm}$ Acquity ${ }^{\circledR}$ Waters as stationary phase, mixture of $0.15 \%$ formic acid-acetonitril $(50: 50, \mathrm{v} / \mathrm{v})$ as mobile phase, and flow rate of $0.5 \mathrm{~mL} / \mathrm{min}$ and detected in positive ionization mode tandem mass spectrometer operated in multiple reaction monitoring (MRM). The MS/MS ion transitions monitored were $m / z 369.05 \rightarrow 176.95$ and $284.95 \rightarrow 193$ for curcumin and IS, respectively. The retention times for curcumin and IS were 1.7 and $1.4 \mathrm{~min}$, respectively, and the linearity range was $1-100 \mathrm{ng} / \mathrm{mL}$ with a coefficient correlation $(r)$ of 0.999 and lower limit of quantitation (LLOQ) of $1 \mathrm{ng} / \mathrm{mL}$. The relative standard deviation (RSD) values of the intra- and inter-assay precisions of the method were below $8.3 \%$ and $12.7 \%$, respectively, while the accuracy ranged from 89.5 to $98.7 \%$ and the extraction recovery of curcumin and IS was up to $86.6 \%$. The data presented show that the method provides specific, very rapid, sensitive, precise, and accurate measurements of curcumin concentrations in human plasma.
\end{abstract}

Keywords: Curcumin, human plasma, liquid-liquid extraction, validation, UPLC-MS/MS

\section{Introduction}

Curcumin, commonly called diferuloylmethane (Figure 1), is the major coloring agent of turmeric (Curcuma longa L.) and javanese turmeric or temulawak (Curcuma xanthorrhiza Roxb). Curcumin has various biological activities, such as antitumor, anti-inflammatory, antivirus, antioxidation, and anti-human immunodeficiency virus (HIV) [1,2]. Various animal models or human studies proved that curcumin is extremely safe even at very high doses. Similarly, the efficacy of curcumin in various diseases including cancer has been well established. The pharmacological safety and efficacy of curcumin make it a potential compound for treatment and prevention of a wide variety of human diseases [3]. However, curcumin has not yet been approved as a therapeutic agent, due to its poor oral bioavailability. The aqueous solubility, chemical stability, poor absorption, and rapid metabolism of the compound have been reported to contribute towards its poor oral bioavailability [3-6]. Curcumin undergoes rapid metabolic conjugation generating mainly curcumin glucuronide and curcumin sulfate, so the level of free curcumin in plasma is very small [6].

Nowdays, many formulations of curcumin have been reported to enhance its bioavailability [7-9]; therefore, the sensitive, specific, and validated analytical method for the compound in human plasma is essential to prove the effectiveness of such formulations. Several methods for determination of the compound in biological samples by high-performance liquid chromatography (HPLC) including HPLC-tandem mass spectrometry (MS/MS) have been developed, but there are only few reports on the determination of the compound by ultra-performance liquid chromatography (UPLC)-MS/MS [9-18]. The UPLC-MS/MS is currently considered as the best choice for supporting bioanalytical studies due to high specificity, sensitivity, and rapidity [19];

* Author for correspondence: hayun.ms06@gmail.com<smiles>COc1cc(/C=C/C(=O)CC(=O)/C=C/c2ccc(O)c(OC)c2)ccc1O</smiles>

Figure 1. Chemical structure of curcumin

however, there has been no report that the method was developed for the determination of curcumin in human plasma [9, 18]. Hence, the aim of this study was to develop a new, rapid, specific, sensitive, and reliable UPLC-MS/MS method for quantitative analysis of curcumin in human plasma, which will be able to provide a variety of options for researchers.

\section{Experimental}

Chemical and reagents. Curcumin (USP Reference standard) was purchased via Megasetia Agung Kimia Co. Ltd. (Jakarta, Indonesia), and diazepam (Internal Standard/IS) of working standard grade was supplied by Centaur Pharmaceuticals PVT Ltd. (Mumbai, India). Acetonitrile and methanol of HPLC grade, and ethylacetate, formic acid, sodium dihydrogen phosphate monohydrate, glaciale acetic acid, and sodium hydroxyde of analytical grade were obtained from Merck Co. Ltd. (Jakarta, Indonesia). Double distilled water was supplied by Ikapharmindo Putramas Co. Ltd. (Bandung, Indonesia), and human plasma was obtained from The Indonesian Red Cross (IRC, Jakarta, Indonesia).

UPLC-MS/MS conditions. The experiment was performed on an ACQUITYTM UPLC system (Waters Corp., Milford, MA, USA) and a Xevo TQD triple quadrupole mass spectrometer (Waters Corp., Manchester, UK) equipped with an electrospray ionization source. All data were acquired in

This is an open-access article distributed under the terms of the Creative Commons Attribution-NonCommercial 4.0 International License (https://creativecommons.org/licenses/by-nc/4.0/), which permits unrestricted use, distribution, and reproduction in any medium for non-commercial purposes, provided the original author and source are credited, a link to the CC License is provided, and changes - if any - are indicated. 
centroid mode by the Masslynx ${ }^{\mathrm{TM}}$ NT4.1 software and analyzed by QuanLynx ${ }^{\mathrm{TM}}$ program (WatersCorp., Milford, MA, USA). The analyte was separated on C18 Acquity ${ }^{\circledR}$ UPLC BEH column $(1.7 \mu \mathrm{m}, 2.1 \mathrm{~mm} \times 100 \mathrm{~mm}$, Waters, Milford, MA, USA). The mobile phase was composed of $0.15 \%$ formic acid solution and acetonitrile $(50: 50, \mathrm{v} / \mathrm{v})$; flow rate was $0.5 \mathrm{~mL} / \mathrm{min}$, and isocratic elution was used. The autosampler was conditioned at $8{ }^{\circ} \mathrm{C}$, and the injection volume was $5 \mu \mathrm{L}$.

The mass spectrometric detector parameters were optimized and set as follows: source temperature as $100{ }^{\circ} \mathrm{C}$, nitrogen desolvation as $400{ }^{\circ} \mathrm{C}$ with a flow rate of $550 \mathrm{~L} / \mathrm{h}$, cone gas of $52 \mathrm{~L} / \mathrm{h}$, dwell time of $0.163 \mathrm{~s}$, and capillary voltage of $3.50 \mathrm{~V}$. The cone voltage was $52 \mathrm{~V}$ for curcumin and $35 \mathrm{~V}$ for the IS, and collision energy was $43 \mathrm{eV}$ for curcumin and $32 \mathrm{eV}$ for the IS. The detector was performed in positive ion mode obtained by electrospray ionization (ESI) $(+)$ technique with capillary voltage was $3.5 \mathrm{kV}$, and quantification was acquired with multiple reaction monitoring (MRM) with ion transition at $m / z 369.05 \rightarrow 176.95$ and $284.95 \rightarrow 193.00$ for curcumin and the IS, respectively.

Preparation of stock and working standard solution. Stock solution of curcumin was prepared at $1.0 \mathrm{mg} / \mathrm{mL}$ in acetonitrile and then serially diluted with mobile phase to obtain the working solutions of curcumin ranging from 25 to $2500 \mathrm{ng} / \mathrm{mL}$. The stock solution of internal standar (IS, diazepam) was prepared at $1.0 \mathrm{mg} / \mathrm{mL}$ in methanol and then serially diluted with methanol to obtain the working solution of diazepam with concentration of $500 \mathrm{ng} / \mathrm{mL}$. All solutions were stored at $4{ }^{\circ} \mathrm{C}$ and brought to room temperature before use.

Calibration standards and quality control (QC) samples used to estimate precision and accuracy of the method were prepared from two separate sets of solutions in human plasma. Calibration standard samples of curcumin $(1,5,10,20,50$, and $100 \mathrm{ng} / \mathrm{mL})$ were obtained by spiking $10 \mu \mathrm{L}$ of the appropriate working solutions to $250 \mu \mathrm{L}$ human plasma (calibration curve in plasma). The QC samples were prepared separately in the same fashion at concentration of $5 \mathrm{ng} / \mathrm{mL}, 30 \mathrm{ng} / \mathrm{mL}$, and $80 \mathrm{ng} / \mathrm{mL}$ for low, medium, and high QC (QCL, QCM, and QCH), respectively.

Preparation of sample solution. A $10 \mu \mathrm{L}$ aliquot of the IS solution $(500 \mathrm{ng} / \mathrm{mL})$ and $5 \mathrm{~mL}$ of ethyl acetate-methanol (95:5) were added to $250 \mu \mathrm{L}$ of plasma sample in polypropylene tube. The mixture was vortex-mixed for $2 \mathrm{~min}$ and centrifuged at $7000 \mathrm{rpm}$ for $5 \mathrm{~min}$. The organic phase was transferred into evaporated tube and evaporated to dryness under nitrogen at $60{ }^{\circ} \mathrm{C}$ for $10 \mathrm{~min}$. The residue was reconstituted with $100 \mu \mathrm{L}$ of mobile phase and transferred into vial, and then $5 \mu \mathrm{L}$ aliquot of the resulting solution was injected into the UPLC-MS/ MS system for analysis.

Method validation. Validation of the quantitative UPLCMS/MS method was assessed including selectivity, linearity, lower limit of quantitation (LLOQ), precision and accuracy, recovery, matrix effect, and stability of the analytes in biological matrix according to the European Medicines Agency (EMEA) guidelines on bioanalytical method validation Committee for Medicinal Products for Human Use [17].

Specificity. The selectivity of the method was evaluated by analyzing six blank plasma and spiked plasma at the LLOQ. The peak areas of the endogenous interference co-eluted with the analytes should be less than $20 \%$ of the peak area of the LLOQ standard and less than $5 \%$ of the peak area of the IS.

Linearity. Calibration standards were prepared and analyzed by plotting the peak area ratios of the analyte to the IS versus the nominal concentration using a linearly weighed regression method in triplicate. Calibration curves were considered acceptable when the correlation coefficient $(r)$ was greater than 0.99 and the bias of the calculated concentrations was within $\pm 15 \%$ of the nominal concentrations, except the LLOQ with an allowed deviation of $\pm 20 \%$.

Lower limit of quantification. LLOQ was established by analyzing six blank plasma samples spiked with $1 / 2$ or $1 / 4$ of the lowest concentration of curcumin in the sample. The analyte response should be identifiable, discrete, and reproducible with acceptable precision and accuracy (less than 20\% for each criterion).

Accuracy and precision. Accuracy and precision were evaluated by assessing six replicates of the QC samples at four concentrations levels (LLOQ, low, medium, and high) on three consecutive validation days. Intra- and inter-day precisions (RSD, relative standard deviation) were required not to exceed $15 \%$, and accuracy (RE, relative error) should be within $\pm 15 \%$.

Carry over. Carry over was assessed by injecting blank samples after calibration standard at the upper limit of quantification. The measured peak area should not be greater than $20 \%$ of the peak area of the analyte at lower limit of quantification (LLOQ) and 5\% of the peak area of the internal standard, respectively.

Recovery and matrix effect. Recovery values (\%) were calculated at three QC levels (QCL, QCM, and QCH) by comparing the peak areas of the regularly processed QC samples with those of spiked post-extraction samples. The \% coefficient of variance $(\mathrm{CV})(\%)$ of the recovery values should be less than $15 \%$. Blank plasma from six lots was extracted and then spiked with curcumin at concentration of QCL and QCH to evaluate the matrix effect (ME) (\%) of the analyte. The peak area in spiked plasma post-extraction samples was then compared with those of standard solutions containing the analyte at equivalent concentrations. The $\% \mathrm{CV}$ of the ME should not be more than $\pm 15 \%$.

Stability. Stability of curcumin in plasma was evaluated at concentration of 5.00 and $80.0 \mathrm{ng} / \mathrm{mL}$ as low and high QC samples (QCs) in three replicates for each concentration under different storage conditions. Sample stability was tested by analyzing the QCs after short-term storage (kept at ambient temperature for $24 \mathrm{~h}$ ) and long-term storage (at $-20{ }^{\circ} \mathrm{C}$ for 49 days) as well as after three freeze-thaw cycles. Moreover, the stability of curcumin in post-preparative samples in the auto-sampler at $4{ }^{\circ} \mathrm{C}$ for $24 \mathrm{~h}$ and stability of stock solutions at room temperature for $24 \mathrm{~h}$ and at refrigerator $\left(-4{ }^{\circ} \mathrm{C}\right)$ were also analyzed.

\section{Results and Discussion}

The UPLC-MS/MS is currently considered as the best choice for supporting bioanalytical studies due to high specificity, sensitivity, and rapidity [19]; however, there are only few reports on the determination of the compound by UPLC-MS/MS, and no report of the method was developed for the determination of curcumin in human plasma $[9,18]$. Here, we described the development and validation of UPLC-MS/MS method for quantitative analysis of curcumin in human plasma.

\section{Method Development}

Selection of IS. In LC-MS, an IS should be an isotropically labeled compound or be as similar in physiochemical properties to the target analyte as possible and elute as close to it as possible [20, 21]. Diazepam was chosen as the IS because it has similarity with curcumin in ionization response and extraction recovery in ESI-MS and a close elution pattern. The compound was also used as IS for quantification of curcumin using LC-MS/MS method reported earlier [13]. 
Optimization of chromatographic conditions. The composition of mobile phase plays a critical role in achieving good chromatographic behavior and appropriate ionization. The mixture consisting of $0.15 \%(\mathrm{v} / \mathrm{v})$ of formic acid in water and acetonitrile in the ratio of 50:50 (v/v) with a flow rate of $0.5 \mathrm{~mL} / \mathrm{min}$ was found to be better in terms of peak shapes (Tf $<2)$, resolution $(R>1.5)$, and column pressure $(<12,000$ psi). Addition of $0.15 \%$ formic acid to the mobile phase was useful to increase MS response. The chromatographic conditions allow a short run time of $3.0 \mathrm{~min}$. The retention times for curcumin and IS were observed at 1.7 and $1.4 \mathrm{~min}$, respectively.

Optimization of mass conditions. In order to optimize ESI condition for curcumin and diazepam as IS, the MS parameters were tuned in positive ionization mode. By direct injecting standard solutions of cucumin and the IS, the mass spectra for curcumin and the IS were obtained. The spectra showed a high intensity signal at $\mathrm{m} / \mathrm{z} 369.05$ and $\mathrm{m} / \mathrm{z} 284.95$, respectively as protonated molecular ions $[\mathrm{M}+\mathrm{H}]^{+}$. The product ion of mass spectra for curcumin and IS resulting from the fragmentation process were observed at $\mathrm{m} / \mathrm{z} 176.95$ and 193.00, respectively (Figure $2 \mathrm{a}$ and $\mathrm{b}$ ). Following the optimization of mass spectrometry conditions, the quantification was acquired with multiple reaction monitoring (MRM) with ion transition at $m / z 369.05 \rightarrow 176.95$ and $284.95 \rightarrow 193.00$ for curcumin and the IS, respectively.

Optimization of sample preparation. Sample solution was prepared using liquid-liquid extraction (LLE) method. The method was selected because of relatively low cost and good extraction efficiency as well as a simple procedure. Various extraction solvents were investigated, but the mixture of ethyl acetate and methanol in the ratio of 95:5 $(\mathrm{v} / \mathrm{v})$ was found to be most effective for extraction of both curcumin and diazepam (IS) in terms of sample cleaning and extraction yield.

\section{Method Validation}

Specificiity. The representative chromatograms resulting from the LC-MS/MS analysis of extracts of $250 \mu \mathrm{L}$ plasma from blank plasma sample (A) and spiked LLOQ curcumin $\left(1 \mathrm{ng} / \mathrm{mL}, t_{\mathrm{R}}=1.7 \mathrm{~min}\right)$ and IS (20 ng/mL, $\left.t_{\mathrm{R}}=1.4 \mathrm{~min}\right)(\mathrm{B})$ are given in Figure 3. No significantly interfering peaks $(<0 \%)$ due to the endogenous components or reagents were observed for curcumin and IS.

Linearity. The calibration curve over the concentration range of $1-100 \mathrm{ng} / \mathrm{mL}$ was linear and acceptable. The calibration equation obtained was $y=0.0228 x+0.0056(r>0.999)$. The mean accuracy and precision for back calculated of each concentrations of the standard from calibration curve are given in Table 1.

Lower limit of quantification (LLOQ). The LLOQ was $1.00 \mathrm{ng} / \mathrm{mL}$ of curcumin with RSD, and bias of backcalculated concentrations of LLOQ was $1.8 \%$ and $<20 \%$, respectively (Table 2).

Accuracy and precision. The intra- and inter-day accuracies and precisions were shown in Table 3 . The intra- and inter-day accuracies were $89.5-98.7 \%$ and $91.5-98.5 \%$, respectively, and the intra- and inter-day assay precisions were $6.17-8.3 \%$ and $6.5-12.7 \%$, respectively. The data demonstrate that the accuracy and precision values are within the acceptable criteria.

a)

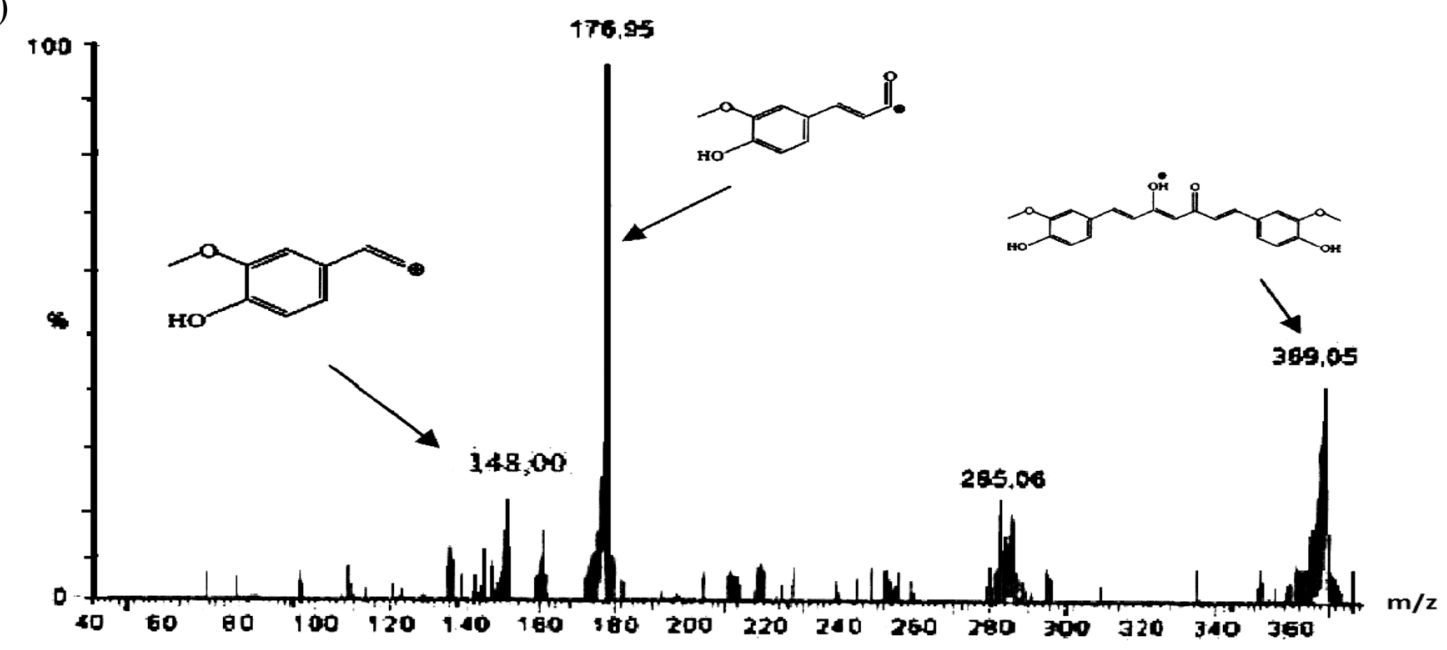

b)

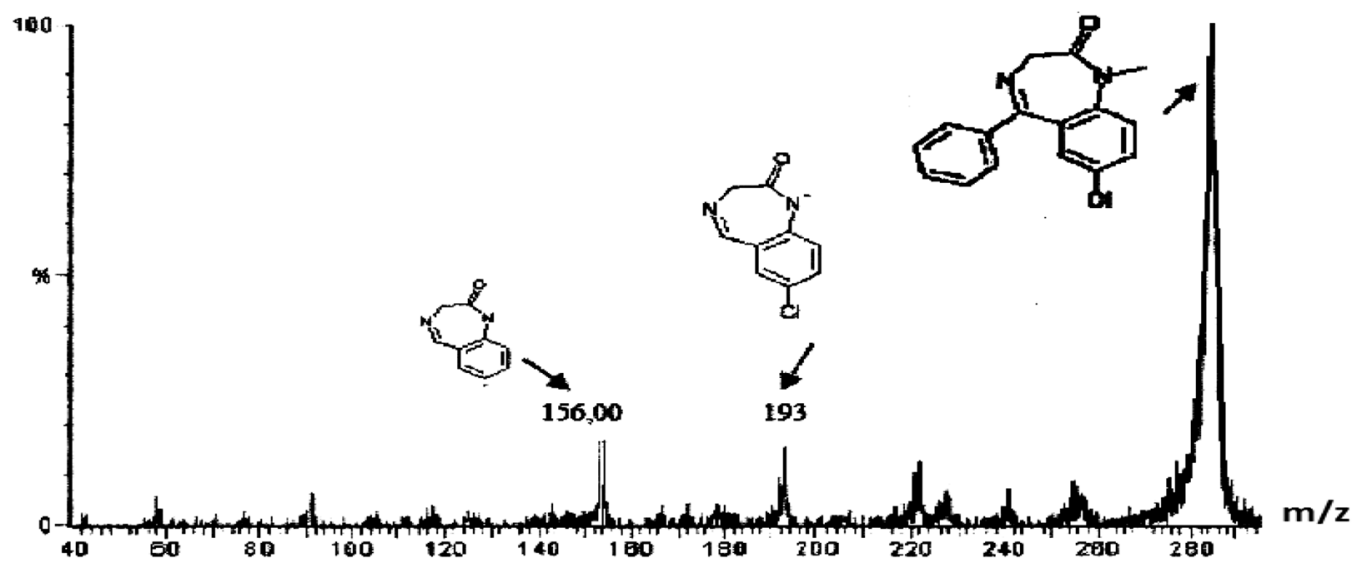

Figure 2. Product ion spectra of (a) curcumin and (b) diazepam as IS 
a) Human blank plasma
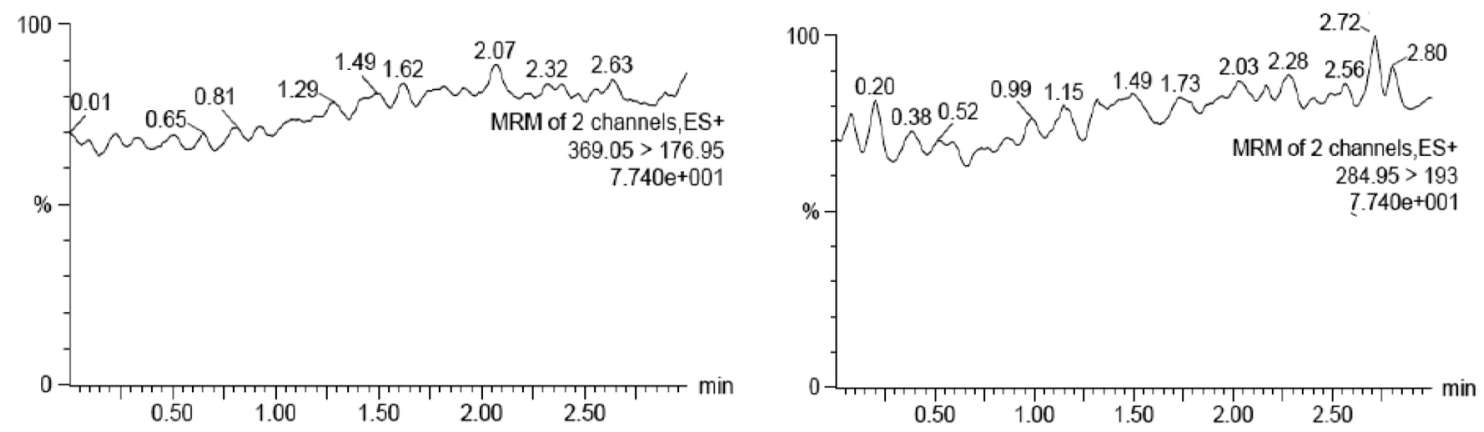

\section{b) LLOQ}
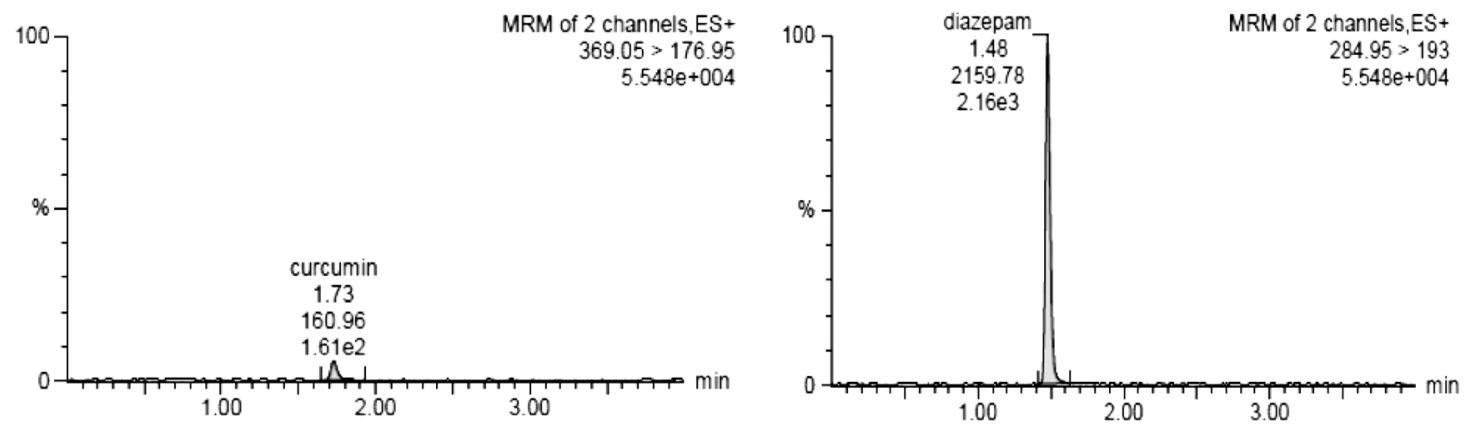

Figure 3. Representative UPLC-MS/MS chromatograms of curcumin (left panel) and IS (right panel) in (a) human blank plasma; (b) human plasma spiked with curcumin at LLOQ and IS

Table 1. The accuracy and precision from calibration curve

\begin{tabular}{lccr}
\hline $\begin{array}{l}\text { Nominal conc. } \\
(\mathrm{ng} / \mathrm{mL})\end{array}$ & $\begin{array}{c}\mathrm{Mean}^{a} \text { calculated } \\
\text { conc. }(\mathrm{ng} / \mathrm{mL})\end{array}$ & $\begin{array}{c}\text { Mean accuracy } \\
(\%)\end{array}$ & $\begin{array}{r}\mathrm{RSD} \\
(\%)\end{array}$ \\
\hline 1.00 & 1.08 & 108.0 & 16.5 \\
5.02 & 4.62 & 92.0 & 7.8 \\
10.04 & 9.54 & 95.0 & 1.9 \\
20.08 & 20.08 & 100.0 & 5.6 \\
50.20 & 52.23 & 104.0 & 5.2 \\
100.40 & 99.45 & 99.1 & 1.1 \\
${ }^{n} n=3$. & & & \\
\hline
\end{tabular}

Table 2. The accuracy and precision from LLOQs

\begin{tabular}{lccc}
\hline $\begin{array}{l}\text { LLOQ conc. } \\
(\mathrm{ng} / \mathrm{mL})\end{array}$ & $\begin{array}{c}\text { Measured conc. } \\
(\mathrm{ng} / \mathrm{mL})\end{array}$ & $\begin{array}{c}\text { Precision } \\
(\% \mathrm{RSD})\end{array}$ & $\begin{array}{c}\text { Accuracy } \\
(\mathrm{RE}, \%)\end{array}$ \\
\hline 1.00 & 0.83 & & -17.0 \\
1.00 & 0.82 & & -18.2 \\
1.00 & 0.80 & 1.8 & -19.8 \\
1.00 & 0.80 & & -19.5 \\
1.00 & 0.83 & & -16.5 \\
\hline
\end{tabular}

Carry over. The measured peak area of the blank sample injected after calibration standard at the upper limit of quantification $(100 \mathrm{ng} / \mathrm{mL})$ was $11.1 \%$ of the peak area of the analyte at lower limit of quantification (LLOQ) and $1.4 \%$ of the peak area of the internal standard, respectively.

Recovery and matrix effect. The mean extraction recoveries of curcumin were $73.0 \pm 2.5 \%, 93.2 \pm 7.1 \%$, and $93.7 \pm 5.1 \%$

Table 3. Intra- and inter-day accuracy and precision

\begin{tabular}{lccccc}
\hline $\begin{array}{l}\text { Nominal conc. } \\
(\mathrm{ng} / \mathrm{mL})\end{array}$ & \multicolumn{2}{c}{ Intra-day } & & \multicolumn{2}{c}{ Inter-day } \\
\cline { 2 - 3 } \cline { 5 - 6 } & $\begin{array}{c}\text { Mean }^{a} \text { accuracy } \\
(\%)\end{array}$ & $\begin{array}{c}\text { Precision } \\
\text { (\%RSD) }\end{array}$ & $\begin{array}{c}\text { Mean accuracy } \\
(\%)\end{array}$ & $\begin{array}{c}\text { Precision } \\
(\% \mathrm{RSD})\end{array}$ \\
\hline 1.00 & 89.5 & 7.0 & & 91.5 & 12.7 \\
5.00 & 91.1 & 6.2 & & 93.4 & 8.5 \\
30.00 & 98.7 & 6.7 & & 98.2 & 9.1 \\
80.00 & 97.5 & 8.3 & & 98.5 & 6.5 \\
${ }_{n}{ }_{n}=5$. & & & & & \\
${ }_{n} n=9$. & & & & & \\
\hline
\end{tabular}

Table 4. Stability of curcumin in human plasma

\begin{tabular}{|c|c|c|c|c|}
\hline \multirow[t]{3}{*}{ Stability experiments } & \multicolumn{4}{|c|}{ Theoretical curcumin conc. (ng/mL) } \\
\hline & 5.0 & 80.0 & 5.0 & 80.0 \\
\hline & \multicolumn{2}{|c|}{$\begin{array}{l}\text { Mean measured } \\
\text { conc. }^{a}(\mathrm{ng} / \mathrm{mL})\end{array}$} & \multicolumn{2}{|c|}{$\begin{array}{l}\text { Mean \% RE } \\
\text { from theoritical }\end{array}$} \\
\hline Short-term storage $\left(24 \mathrm{~h}, 25^{\circ} \mathrm{C}\right)$ & 5.2 & 73.1 & 4.5 & -8.6 \\
\hline Long-term storage ( 49 days, $-20^{\circ} \mathrm{C}$ ) & 5.5 & 70.6 & 10.4 & -11.7 \\
\hline Three freeze-thaw cycles & 5.2 & 71.7 & 3.7 & -10.4 \\
\hline Autosampler $\left(24 \mathrm{~h}, 4^{\circ} \mathrm{C}\right)$ & 5.6 & 71.2 & 11.7 & -11.0 \\
\hline$a_{n}=3$. & & & & \\
\hline
\end{tabular}

$(n=3)$ at the concentration of $5.00,30.00$, and $80.00 \mathrm{ng} / \mathrm{mL}$, with \% CV values of 3.5, 7.6 and $5.5 \%$, respectively, while for the IS was $87.8 \pm 8.7 \%(n=9)$ at concentration of 50.0 $\mathrm{ng} / \mathrm{mL}$ with \% CV value was $9.9 \%$. The data show that the simple LLE procedure extracts the analyte as well as IS from human plasma efficiently. The mean MEs of curcumin were $91.2 \%$ and $96.2 \%$ at the concentration of 5.00 and $80.00 \mathrm{ng} /$ $\mathrm{mL}$, with $\% \mathrm{CV}$ of $3.4 \%$ and $1.3 \%$, respectively, while, for the IS, it was $96.8 \pm 12.9 \%(n=9)$ with $\%$ CV of $13.4 \%$. These data indicate that the ME (ion suppression or enhancement) from human plasma was negligible under the current conditions.

Stability. Storage of stock solutions of curcumin and diazepam (IS) in acetonitrile at room temperature for $24 \mathrm{~h}$ and in refrigerator $\left(-4{ }^{\circ} \mathrm{C}\right)$ for 1 month did not alter the analyte. The stability test results of curcumin in human plasma are given in Table 4. The data indicate that curcumin is stable enough during sample preparation and storage conditions.

\section{Conclusion}

In conclusion, the UPLC-ESI-MS/MS method for quantitative analysis of curcumin in human plasma was succesfully developed and validated. The method provides very rapid, sensitive, and specific measurements of curcumin concentrations; however, the performance of the method has not been 
verified for analysis of the compound in human plasma in vivo.

\section{Conflict of interest}

The authors declare no conflict of interest.

Acknowledgments. We thank the Directorate of Research and Community Services, Universitas Indonesia, Depok, Indonesia, and the Directorate of Research and Community Services as well as Directorate of Higher Education of the Ministry of Research, Technology and Higher Education of the Republic of Indonesia, for the financial support of this research.

\section{References}

1. Anand, P.; Thomas, S. G.; Kunnumakkara, A. B.; Sundaram, C.; Harikumar, K. B.; Sung, B.; Tharakan, S. T.; Misra, K.; Priyadarsini, I. K.; Rajasekharan, K. N.; Aggarwal, B. B. Biochem. Pharmacol. 2008, 76, 1590-1611. 2. Chattopadhyay, I.; Biswas, K.; Bandyopadhyay, U.; Banerjee, R. K. Curr. Sci. 2004, 87, 44-53.

3. Anand, P.; Kunnumakkara, A. B.; Newman, R. A.; Aggarwal, B. B. Mol. Pharmaceutics 2007, 4, 807-818.

4. Pawar, Y. B.; Munjal, B.; Arora, S.; Karwa, M.; Kohli, G.; Paliwal, J. K.; Bansal, A. K. Pharmaceutics 2012, 4, 517-530.
5. Yang, K. Y.; Lin, L. C.; Tseng, T. Y.; Wang, S. C.; Tsai, T. H. J. Chromatogr. B Anal. Technol. Biomed. Life Sci. 2007, 853, 183-189.

6. Vareed, S. K.; Kakarala, M.; Ruffin, M. T. et al. Cancer Epidemiol. Biomarkers Prev. 2008, 17, 1411-1417.

7. Prasad, S.; Tyagi, A. K.; Aggarwal, B. B. Cancer Res Treat. 2014, 46, $2-18$

8. Dutta, A. K.; Ikiki, E. J. Bioequiv. Availab 2013, 6, 1-9.

9. Krishnakumar, I. M.; Abhilash, M.; Gopakumar, G.; Dinesh, K.; Balu, M.; Ramadasan, K. J. Func. Food 2015, 14, 215-225.

10. Ma, Z.; Shayeganpour, A.; Brocks, D. R.; Lavasanifar, A.; Samuel, J. Biomed. Chromatogr. 2007, 21, 546-552.

11. Heath, D. D.; Pruitt, M. A.; Brenner, D. E.; Rock, C. L. J. Chromatogr. B. 2003, 783, 287-295.

12. D'souza, A. A.; Devarajan, P. V. J. Liq. Chromatogr. \& Rel. Tech. 2013, 36, 1788-1801.

13. Wang, X. M.; Zhang, Q. Z.; Yang, J. et al. Trop. J. Pharm. Res. 2012 $11,621-629$.

14. Ramalingam, P.; Ko, Y. T. J. Chromatogr. B. 2014, 969, 101-108

15. Liu, A.; Lou, H.; Zhao, L.; Fan, P. J. Pharm. and Biomed. Anal. 2006, $40,720-727$.

16. Ang, X.; Ma, J.; Ye, Y.; Zhang, Y.; Liu, G.; Zheng, Y.; Li, X.; Wang, X Chromatographia 2011, 73, 605-608.

17. Singh, S. P.; Wahajuddin; Jain, G. K. J. Bioanal. Biomed. 2010, 2, 079-084.

18. Marczylo, T. H.; Steward, W. P.; Gescher, A. J. J Agric. Food Chem. 2009, 57, 797-803.

19. Liu, H.; Wu, P. P.; Yang, M. J.; Men, L.; Lin, H. L.; Zhao, Y. L.; Tang, X.; Yu, Z. G. J. Pharm. Anal. 2016, 6, 32-38.

20. Liu, H. Guideline on bioanalytical method validation, Committee for Medicinal Products for Human Use (CHMP) 2011.

21. Sargent, M. (Ed.); Guide to achieving reliable quantitative LC-MS measurements, RSC Analytical Methods Committee, 2013. 